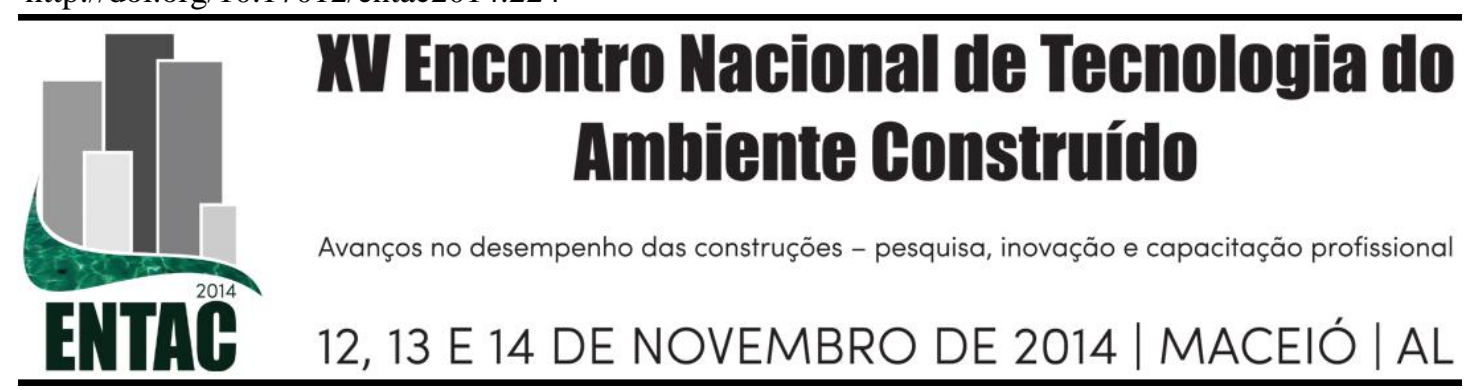

\title{
ESTRUTURAS PRÉ-FABRICADAS EM CONCRETO: ANÁLISE DA COORDENAÇÃO ENTRE FABRICAÇÃO E MONTAGEM
}

\author{
TREVISO, João Pedro (1); ISATTO, Eduardo Luis (2) \\ (1) NORIE/UFRGS, joaopedro89@ hotmail.com, (2) NORIE/UFRGS, isatto@ufrgs.br
}

\begin{abstract}
RESUMO
O emprego de sistemas construtivos pré-fabricados tem crescido no Brasil nos últimos anos, principalmente em virtude da dificuldade de se atender à elevada demanda por obras a partir do emprego de métodos construtivos tradicionais. Soluções baseadas em estruturas pré-fabricadas em concreto têm se mostrado especialmente atraentes na construção e revitalização de estádios de futebol, tendo em vista a possibilidade de redução de prazos de execução e ganhos de produtividade. Porém, a adoção de tecnologias baseadas na pré-fabricação traz consigo uma dificuldade adicional no que diz respeito ao esforço de coordenação necessário entre fábrica e obra. O presente artigo tem como objetivo analisar criticamente tanto os aspectos negativos envolvidos na coordenação entre fabricação e montagem de estruturas pré-fabricadas de concreto, assim como as medidas tomadas para amenizá-los. A partir de um estudo de caso envolvendo a construção de um estádio de futebol padrão FIFA em Porto Alegre-RS, foi possível identificar um conjunto de fatores responsável por afetar negativamente e forma expressiva o grau de dificuldade observado na coordenação entre a fabricação dos componentes e sua montagem em obra. O estudo sugere que esta integração é gravemente afetada pelo descompasso entre as sequências de produção em fábrica e montagem em obra, e indica que seus efeitos negativos podem ser amenizados a partir de soluções que envolvem decisões tomadas tipicamente durante o PSP e o PCP das obras.
\end{abstract}

Palavras-chave: Estruturas pré-fabricadas, Gestão da Cadeia de Suprimentos, Coordenação.

\begin{abstract}
The use of precast construction systems has grown largely in the last few years in Brazil, mainly due to the difficulty of the traditional methods on meeting the high demand for constructions. Solutions based on precast concrete structures have been shown attractive especially for the construction and revitalization of soccer stadiums, due to the possibility for deadline reduction and gains on productivity. However, the adoption of technologies based on precast methods is associated to difficulties regarded to the coordination between the factory and the construction site. This article aims to discuss the aspects that are involved in the coordination between the manufacture and the assembly of precast concrete structures, as well as the actions taken in order to mitigate them. Based on a case study of a FIFA standard soccer stadium construction, in the Brazilian city of Porto Alegre, it was possible to identify a group of factors responsible to negatively affect the grade of the coordination difficulty between the manufacture and the assembly in the construction site of the precast components. This study suggests that this integration is severely affected for the differences on the rate of production between the manufacture and the assembly sequences, and also proposes that these negative effects can be mitigated by solutions involving decisions taken typically during the Production System Project and the Production Planning and Control stages.
\end{abstract}

Keywords: Precast Structures, Supply Chain Management, Coordination.

\section{INTRODUÇÃO}

Nos últimos anos, a indústria da construção civil brasileira se manteve aquecida em função de investimentos destinados a viabilizar a realização da Copa do Mundo de 2014 
e das Olimpíadas de 2016 no País. De acordo com o Tribunal de Contas da União (2012), apenas para o primeiro evento foram orçados $\mathrm{R} \$ 27,4$ bilhões em obras, as quais contemplam a construção e reforma de estádios e intervenções na infraestrutura urbana das cidades-sede.

Um volume tão grande de obras em andamento evidenciou alguns problemas correntes na construção civil, tais como escassez de mão de obra e de materiais, baixa produtividade e serviços de qualidade insatisfatória, os quais têm levado as construtoras a buscarem soluções em práticas até então pouco exploradas. Neste novo cenário, destacam-se o uso de sistemas de montagem, máquinas, equipamentos e materiais préprontos, além de uma nova abordagem no planejamento das obras. Nesse sentido, Vrijhoef e Koskela (2000) apontam que a externalização de parte da produção em obra para a cadeia de suprimentos é uma das alternativas utilizadas para reduzir custos e prazos nos empreendimentos de construção.

Nesse contexto, insere-se a adoção de estruturas em concreto pré-fabricado, amplamente utilizadas em edificações, pontes, túneis, muros de arrimo e reservatórios, bem como estádios de futebol. Basicamente, este método construtivo se caracteriza por moldar previamente os elementos estruturais de concreto, fora ou dentro do canteiro de obras, e, posteriormente, montá-los em suas posições definitivas, conforme projeto estrutural e sequência de montagem. No entanto, os ganhos de produtividade obtidos através da préfabricação são altamente dependentes da escala de produção, o que por sua vez afeta o sequenciamento, o tamanho de lotes e a ordem de expedição das peças pré-fabricadas os quais nem sempre são aqueles necessariamente demandados pela obra. Em caso de obras que envolvem um grande número de tipos distintos de componentes, os problemas de integração fábrica-obra advindos destes fatores podem comprometer gravemente os ganhos de custos e prazos esperados pelo emprego da pré-fabricação.

Neste sentido, o presente artigo tem como objetivo a discussão tanto dos aspectos negativos que envolvem a coordenação entre as etapas de fabricação e montagem de estruturas pré-fabricadas de concreto, quanto das medidas implementadas para amenizálos. Para isto, toma-se como estudo de caso a construção de um estádio de futebol padrão FIFA, com capacidade para 60 mil espectadores, na cidade de Porto Alegre-RS.

\section{PRÉ-FABRICADOS EM CONCRETO}

Inúmeros são os elementos em concreto pré-fabricado empregados atualmente no Brasil. Dentre eles, El Debs (2000) destaca o emprego de lajes alveolares (em concreto protendido) e as vigas de seção I, T e L. O processo executivo das lajes alveolares ocorre em pistas de protensão, por extrusão ou por formas deslizantes. De maneira geral, os fabricantes possuem pistas com largura de $1,20 \mathrm{~m}$ e comprimento variando entre 80 e $150 \mathrm{~m}$, nas quais estas pistas são inteiramente concretadas de uma única vez para posteriormente receberem o corte no tamanho específico das lajes, como apresentado na Figura 1.

Já a produção de vigas padronizadas ocorre em pistas de largura fixa, havendo o uso de formas metálicas estruturadas, enquanto que a execução de seções especiais é realizada em formas de madeira. $\mathrm{O}$ transporte até os canteiros de obras é realizado por caminhões, nos quais a quantidade de elementos transportados por viagem é limitada por regras de tráfego que regulam peso, largura e comprimento dessas peças. Para a montagem de estruturas, Oliveira (2007) indica o uso de gruas e guindastes. A instalação de gruas nas obras pode trazer uma série de benefícios: redução do número de operários, agilização 
do sistema construtivo e possibilidade de içamento de grandes peças pré-fabricadas, como pilares, lajes, vigas e fachadas.

Assim como as gruas, os guindastes podem cumprir função semelhante em obra, porém estão atribuídos a altos valores de aluguel. Portanto, para que seus benefícios sejam maximizados, é necessário que haja um planejamento adequado para itens como localização na obra, proximidade com estoques, áreas de carga e descarga e vias de circulação (OLIVEIRA, 2007).

Figura 1 - Processo executivo de lajes alveolares: (a) preparação da pista; (b) concretagem e (c) corte e desfôrma.

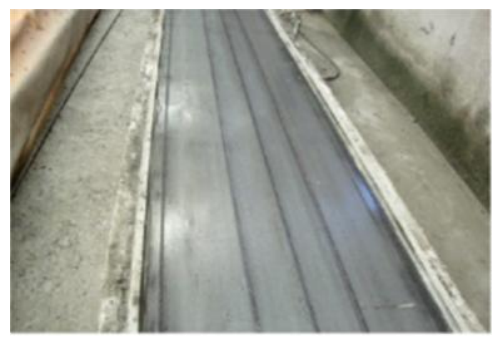

(a)

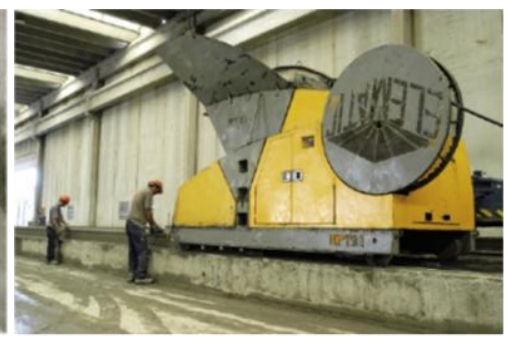

(b)

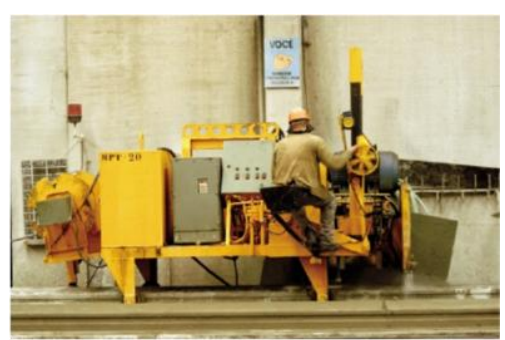

(c)

Fonte: adaptado de VENTURINI (2011)

\section{PLANEJAMENTO E CONTROLE EM OBRAS DE CONSTRUÇÃO E NO AMBIENTE FABRIL}

O planejamento e o controle envolvem dois aspectos fundamentais, o planejamento do sistema de produção (que envolve a estrutura de fabricação) e o planejamento e controle da produção (o que será produzido e quando).

\subsection{Projeto do Sistema de Produção}

De acordo com Hopp e Spearman (1996), um sistema de produção pode ser definido como "uma rede de processos orientados por um objetivo, através da qual entidades fluem", considerando a visão de produção como fluxo e as interações entre os diversos processos que compõem o sistema de produção. Para Slack et al. (1997), a maneira de projetar o sistema de produção que produz um produto tem um impacto significativo na habilidade da produção em atender às necessidades de seus consumidores. Erros na concepção de processos - local inadequado, capacidade subdimensionada, tecnologia ultrapassada, pessoal defasado - tendem a não satisfazer os consumidores, já que ocorrem deficiências no desempenho de suas funções.

Em um ambiente industrial, tais decisões são normalmente tomadas em um estágio anterior ao início da produção, geralmente quando da instalação da fábrica, e uma vez tomadas sua reversão é difícil ou impraticável. No caso das obras de construção, porém, o projeto do sistema de produção ocorre de forma distinta. Dado que a produção é orientada por projetos, os quais possuem um final previamente definido, o sistema de produção assume também ele uma natureza temporária.

Assim, conforme Schramm (2004), “o projeto do sistema de produção (PSP) deve ser encarado como uma atividade de gestão da produção que apresenta interfaces tanto com o processo de desenvolvimento do produto, tanto com o processo de planejamento da produção." O mesmo autor ainda indica que o PSP deve vincular o produto a ser produzido e o sistema de produção utilizado para tal, de forma que o processo de planejamento e controle se torne mais simples e efetivo. Em relação ao escopo do PSP 
para obras de construção, este é muito semelhante àquele presente na manufatura, que, segundo Schramm (2004), inclui decisões acerca do nível de integração vertical (comprar ou fazer), arranjo físico e fluxos, capacidade de produção, sincronização da produção e projeto dos processos produtivos. O planejamento do leiaute geral do canteiro de obras (também denominado macro-leiaute) faz parte integrante do PSP.

\subsection{Planejamento e Controle da Produção}

\subsubsection{Planejamento e controle da produção em obras de construção}

Formoso et al. (2001) propõem um modelo para o processo de planejamento e controle de empreendimentos baseado no Last Planner, idealizado por Ballard (2000). O Last Planner engloba três níveis de planejamento (longo, médio e curto prazos) com crescente nível de detalhamento e um caráter que avança do estratégico para o operacional.

No planejamento de longo prazo, o principal produto gerado é o plano mestre (master plan) do empreendimento, nos quais são definidos os ritmos em que deverão ser executados os principais processos de produção - são utilizados recursos computacionais, gráficos de Gantt, redes CPM e outros indicadores. Envolve ainda a aquisição de recursos de longo ciclo de duração ou baixa repetitividade, os quais devem ser adquiridos a partir da programação de serviços do plano de longo prazo (FORMOSO et al., 2001).

O planejamento de médio prazo, comumente denominado de lookahead planning ("planejamento olhando para frente"), promove a vinculação entre o plano mestre e os planos operacionais, através da divisão e da segmentação do plano mestre em pacotes de trabalho com horizontes de dois ou três meses. Como um de seus principais objetivos, está a remoção das restrições do sistema de produção, identificando as informações e recursos necessários para a realização dos lotes de trabalho. Ainda, nesta etapa, deve ocorrer o planejamento dos fluxos físicos de produção, e o detalhamento do projeto de leiaute do canteiro (micro-leiaute, associado com a realização de determinados processos ou fases da obra) e do plano de ataque à obra (FORMOSO et al., 2001).

No planejamento de curto prazo, ocorre o fracionamento das atividades planejadas no nível tático em pacotes menores de trabalho, denominados de tarefas, havendo a alocação dos recursos necessários para executá-las. Neste ciclo, busca-se o engajamento das equipes com as metas estabelecidas, o que torna este ciclo também denominado como commitment planning - planejamento de comprometimento. A elaboração do plano se inicia pela listagem de todas as tarefas passíveis de serem realizadas no período, fazendo-se sua distribuição às equipes de trabalho, por ordem de prioridade, de forma que sejam distribuídos pacotes de trabalho semanais a cada uma destas equipes (FORMOSO et al., 2001).

\subsubsection{Planejamento e controle da produção de elementos pré-fabricados}

Conforme Prieto (1968), um programa de pré-fabricação deve ser elaborado agrupando as peças a serem produzidas por famílias e tipos. As famílias compõem um grupo mais amplo de peças, as quais possuem as mesmas dimensões exteriores e, dentro de cada família, existem diferentes tipos de peças em função dos elementos incorporados. Assim, as mesmas formas produzem os diferentes tipos que compõem uma mesma família. 
Uma vez definidas estas categorias, pode-se programar a produção conforme a demanda de diferentes frentes e os níveis de estoque de materiais, especificando-se assim as programações diárias de fabricação. A partir do cronograma de montagem, que ordena o dia e a hora que cada peça deve ser colocada em obra, se estabelece o programa de expedição, organizando cada transporte de forma que a carga de peças seja a máxima permitida pelos transportadores. A carga em fábrica deve se realizar em ordem inversa à de sua colocação em obra (PRIETO, 1968).

Fabro (2012) indica que estoques intermediários são formados entre a fabricação e a montagem em razão da diferença entre as suas sequências: se por um lado a fabricação busca explorar o fator escala - produzindo a maior quantidade possível de uma mesma família e tipo de produtos simultaneamente, por outro a montagem tende a ser favorecida pelo sequenciamento em setores da obra e pelo emprego de lotes menores de montagem. Conforme Ohno (1997), reprogramações, atrasos e mudanças na sequência de montagem tendem a aumentar tais estoques - pois peças já produzidas podem ter sua montagem postergada - ou ainda determinam a necessidade de fabricação, em regime de urgência, de peças que não estavam anteriormente programadas, com evidentes efeitos negativos sobre a escala de fabricação.

\section{MÉTODO DE PESQUISA}

O presente artigo tem como estudo de caso o processo construtivo de um estádio de futebol com capacidade para 60 mil espectadores (Tabela 1), cuja estrutura é constituída por elementos de concreto moldado in loco (pilares e escadas) e pré-fabricados (vigas e lajes alveolares), ilustrados na Figura 2. A indústria fabricante das 1.658 vigas e 11.992 lajes alveolares estava situada à cerca de $2,5 \mathrm{~km}$ de distância do canteiro de obras, sendo o seu transporte realizado em caminhões do tipo carreta, comportando dez lajes ou três vigas por viagem.

Tabela 1 - Dados do empreendimento

\begin{tabular}{c|c|c|c|c}
\hline Área Terreno & Área Constr. & Pavtos. & Níveis arquibancada & Prazo \\
\hline $380.000 \mathrm{~m}^{2}$ & $192.000 \mathrm{~m}^{2}$ & 8 & 4 & 30 meses \\
\hline
\end{tabular}

Fonte: TREVISO (2013)

$\mathrm{Na}$ etapa de montagem da estrutura, a gerência da obra utilizava como indicadores de produção a quantidade de peças montadas e a aderência ao cronograma físico planejado. O primeiro parâmetro era expresso em peças/mês, oriundo de medições diárias realizadas por estagiários, os quais preenchiam uma tabela padrão contendo data, código da peça montada, quantidade, setor, pavimento, equipamento utilizado e turno de montagem. O segundo era controlado com base no projeto estrutural dos pavimentos, nas quais as peças montadas eram identificadas com cores distintas, associadas a um período (mês) específico, a partir das quais havia a comparação com o planejamento de montagem.

Com base nestes dados, a gerência da obra concluiu que o ritmo de produção até então seria insuficiente para concluir a montagem até o seu deadline. Uma vez que esta era uma atividade precedente a várias outras - tais quais alvenarias, acabamentos, instalações, montagem da cobertura, colocação da fachada e plantio do gramado, o cumprimento do prazo de entrega do empreendimento, desta forma, também poderia estar comprometido. 
Desde então, passaram a ser realizadas observações em campo e reuniões periódicas com o intuito de discutir as possíveis fontes de perdas e os agentes causadores da baixa produtividade verificada, bem como que medidas poderiam ser tomadas para atenuá-los. Desta forma, ao longo do processo produtivo foram planejadas e executadas ações fundamentalmente empíricas, as quais eram avaliadas durante as reuniões juntamente com os novos dados referentes aos indicadores de produção. Nesse contexto, havia reuniões em que participava apenas o corpo técnico do empreendimento (gerentes, engenheiros, mestre-de-obras, estagiários), e outras em que participavam ainda representantes da fabricante (coordenadores de produção e financeiro).

Maiores detalhes sobre o método empregado, assim como outros resultados do estudo que serviu de base para o presente artigo, podem ser obtidos em Treviso (2013), no qual uma análise do sistema produtivo é abordada de maneira mais profunda.

Figura 2 - Corte esquemático

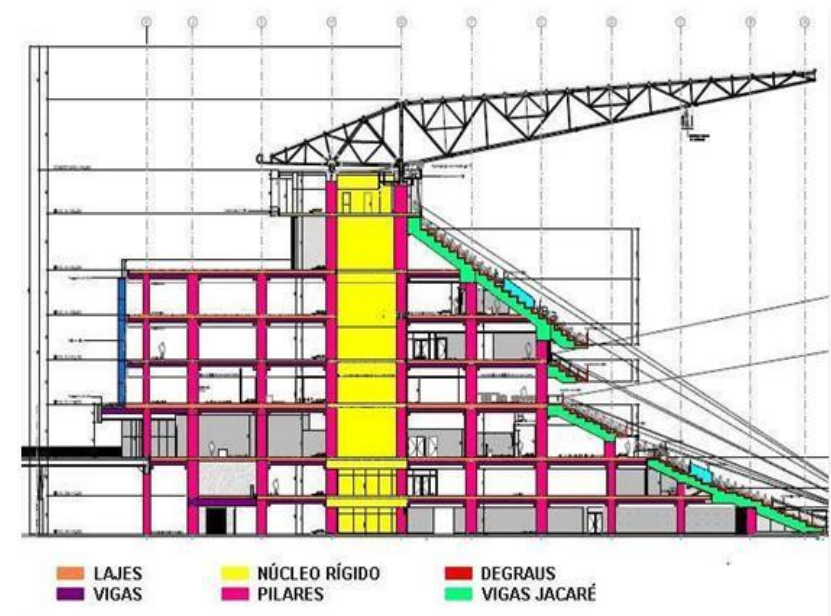

Fonte: TREVISO (2013)

\section{COORDENAÇÃO ENTRE FABRICAÇÃO E MONTAGEM DE ESTRUTURAS PRÉ-FABRICADAS EM CONCRETO}

\subsection{Identificação dos aspectos negativos e seus efeitos}

Uma série de aspectos negativos foi observada ao longo dos processos para execução da estrutura, os quais são apresentados a seguir, assim como os efeitos por eles gerados. Dado que tais aspectos apresentam relações entre si, essas relações são discutidas em sequência.

\subsubsection{Variedade dos elementos pré-fabricados}

A variedade de famílias de lajes e vigas foi uma das dificuldades recorrentes ao processo de montagem. Do total de 11.992 lajes alveolares, 6.953 eram de famílias diferentes. Estas variações ocorriam em função dos três valores de sobrecarga existentes para cálculo em projeto $\left(50,70\right.$ e $\left.100 \mathrm{kN} / \mathrm{m}^{2}\right)$ e por variações geométricas (comprimento, largura e espessura). Ainda, existiam também diferentes disposição e combinação das armaduras de protensão nas peças produzidas. 


\subsubsection{Descompasso entre as sequências de fabricação e montagem}

$\mathrm{Na}$ fabricação, o principal fator negativo refere-se à programação e ao sequenciamento das peças a serem produzidas. Com o intuito de otimizar os recursos materiais, a fabricante das lajes e vigas executava todas as peças de uma mesma família ou tipo em um mesmo período de tempo.

No caso das lajes, por exemplo, era assim realizado para que se produzissem todas aquelas com a mesma disposição e combinação de armaduras, uma vez que, neste processo de fabricação, a pista é inteiramente concretada para que posteriormente sejam executados os cortes conforme a dimensão especificada. Logo, mesmo aquelas lajes que não seriam utilizadas no curto prazo eram produzidas antes de serem efetivamente necessárias.

\subsubsection{Estoques excessivos}

Como a fabricante mantinha estoques mínimos nas suas instalações, dadas as limitações de espaço, toda a produção - mesmo aquela produzida antecipadamente - era enviada quase que imediatamente para a obra, onde era então armazenada. Alguns problemas estão associados a esta situação:

a) falta de espaço para armazenagem: foram necessários três locais distintos para armazenagem das peças, distantes entre si, com um evidente impacto negativo sobre os custos de transporte e manuseio das peças;

b) controle dos estoques: na medida em que aumentavam as quantidades e variedades em estoques, os métodos de controle empregados tornavam-se mais dispendiosos e menos precisos, agravado pela perda de etiquetas de identificação das peças devido a intempéries. Com isto, peças deixavam de ser localizadas, levando à substituição por outras peças do estoque (com as devidas adaptações como, por exemplo, cortes adicionais), as quais eram novamente solicitadas à fábrica;

c) dificuldades de manuseio, pois frequentemente as peças necessárias encontravam-se nas partes inferiores das pilhas, necessitando movimentação de toda uma parte do estoque para que se tornasse possível o acesso até as mesmas;

d) desgaste das peças devido a intempéries.

\subsubsection{Interações entre os aspectos negativos identificados}

Os efeitos negativos observados apresentam diversas interações entre si, as quais devem ser bem compreendidas para que se direcionem de forma eficaz as medidas mitigatórias a serem adotadas para eliminar ou atenuar os problemas observados. As medidas mitigatórias implementadas, descritas na seção seguinte, visam os aspectos negativos identificados em vermelho na Figura 3.

A partir desta figura, é possível observar que os estoques elevados são causados principalmente pela falta de coordenação entre as lógicas de programação da produção da fábrica (programação de fabricação) e da obra (programação da montagem). Tais estoques resultam em diversos efeitos negativos mencionados: falta de espaço para estocagem, dificuldades de manuseio, desgaste e falhas no controle (controle ineficiente).

Este último acarreta dificuldades na localização das peças em estoque, a qual também é afetada pela perda das etiquetas e pela variedade de peças, o que ocasiona o aumento 
nos tempos de espera (atrasos para localizar as peças necessárias) e, eventualmente, a substituição de peças por outras peças semelhantes. Com isto, as peças utilizadas em substituição farão falta no futuro, gerando a revisão de pedidos de peças e, consequentemente, afetando a programação da montagem. A figura também indica que a variedade de peças é um parâmetro relevante, pois afeta tanto a programação de fabricação (tornado-a mais complexa) como a aumenta a dificuldade de localização das peças em estoque.

\section{Figura 3 - Interações entre os aspectos negativos identificados}

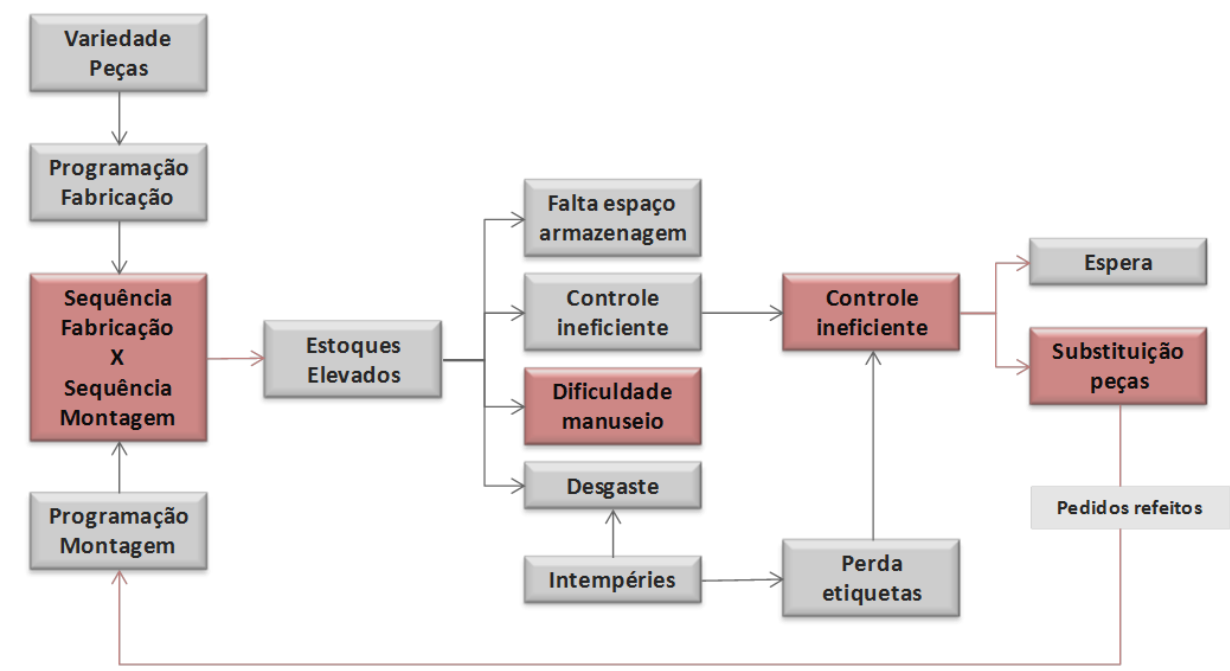

Fonte: elaborado pelos autores

\subsection{Medidas mitigatórias implementadas}

\subsubsection{Alinhamento da produção}

Uma das primeiras medidas implementadas foi buscar um melhor alinhamento entre a produção em fábrica às reais necessidades da obra. Foi elaborada uma programação de produção a ser seguida a partir da definição de uma sequência de montagem - a qual foi apresentada à empresa fabricante, identificando-se aqueles elementos que seriam utilizados no curto prazo para a obra,.

Como critério utilizado para determinação das séries de fabricação, escolheu-se a armadura de protensão das lajes alveolares. Primeiramente, foram verificadas as combinações de cabos de protensão existentes nas peças que seriam produzidas para os setores que, no curto prazo, deveriam ser montados. Este processo contemplou, inicialmente, 780 lajes alveolares que estavam programadas para serem montadas no curto prazo. Enquanto isso, para atender à demanda de longo prazo da obra, as demais peças foram produzidas em plantas industriais de Santa Catarina e do Paraná, com incremento do custo de transporte para a construtora.

\subsubsection{Programação de expedição}

Como complemento à ação descrita acima, foi implementada ainda uma programação de expedição dos elementos produzidos. Para isto, seguiu-se a ordem e a sequência de montagem das lajes alveolares na estrutura, correspondente pela aplicação dos elementos que estão na borda interna (voltada para o centro do campo) em direção àqueles mais próximos à fachada (Figura 4). 


\section{Figura 4 - Ordem de aplicação dos pré-fabricados à estrutura}

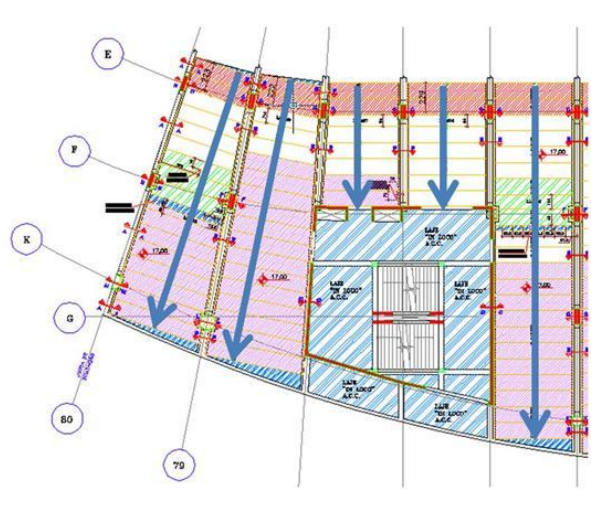

Fonte: TREVISO (2013)

Portanto, pôde-se definir, a partir deste ordenamento implementado, como estariam distribuídas as peças pré-fabricadas nos caminhões que fariam o transporte fábrica-obra. As cargas a serem entregues em obra passaram a ser programadas conforme a montagem a ser realizada. Com isso, por vezes, foi possível suprimir a etapa estoque tanto em fábrica (após a fabricação) quanto no canteiro. Depois de produzidas, as lajes alveolares poderiam seguir diretamente para a obra, enviando-as diretamente para montagem, conforme o posicionamento das peças no pavimento.

\subsubsection{Identificação visual de peças}

Foram atribuídas cores a cada um dos dez setores ao qual o estádio foi dividido e, a partir disto, identificadas com tinta spray cada uma das peças pré-fabricadas conforme seu respectivo setor de colocação. Como resultado, tornou-se possível a pronta identificação do local de aplicação das peças à estrutura por parte das equipes de montagem, além de facilitar os processos de busca e localização nos estoques (TREVISO, 2013).

\subsubsection{Mudanças no leiaute do canteiro de obras}

A redução do estoque em obra permitiu que os três locais distintos para armazenagem fossem centralizados em uma única área anexa ao canteiro, a partir da qual eram enviados aos seus locais de aplicação à estrutura conforme sua sequência de montagem. Um estoque temporário foi organizado no espaço central do estádio, depositando o material próximo aos seus locais de utilização, reduzindo assim a necessidade de manobras e movimentação dos equipamentos.

\subsubsection{Confecção de peças de carga e dimensão máximas}

Foram produzidas algumas lajes alveolares de dimensão e capacidade de carga máximas, de forma que estas pudessem atuar como substitutas de qualquer peça faltante. Para isso, seriam necessários apenas ajustes dimensionais, como cortes longitudinais ou execução de chanfros, realizados simplesmente com uma máquina de corte.

\subsubsection{Resultados da implementação das medidas}

As medidas mitigatórias implementadas resultaram em um evidente impacto positivo no processo de montagem, estando associadas a um expressivo aumento da quantidade de peças instaladas por mês na estrutura, na comparação com os índices de produção anteriores (TREVISO, 2013). 


\subsection{Discussão}

A partir dos aspectos negativos observados e das medidas mitigatórias adotadas pela construtora, fica evidente que uma das razões para o descompasso entre a fabricação e a montagem das peças reside nas diferentes sequências de montagem: se, por um lado a fábrica busca explorar a escala de fabricação, a obra adota uma lógica distinta pela montagem. Isto resulta em elevados estoques intermediários, que agravam tal descompasso na medida em que favorecem o extravio de peças e sua substituição por outras, demandando encomendas não previstas e a mudança nas ordens de fabricação.

Foi possível observar que as soluções implementadas envolvem decisões tipicamente tomadas durante o PSP e o PCP da obra. Quanto à medida de alinhamento da produção da fábrica à sequência de montagem, a definição desta última envolve decisões que integram tanto o escopo do PSP (arranjo físico e fluxos, capacidade e sincronização da produção, etc.) como o planejamento de médio e curto prazo da obra (identificação de restrições e controle da efetiva liberação dos pacotes de trabalho).

A programação de expedição implementada vai ao encontro das recomendações indicadas por Prieto (1968), o qual sugere que as programações de fabricação e expedição devem estar associadas à montagem e ao estoque em obra. Desta forma, entende-se que a integração destas programações poderia ter sido discutida na etapa de preparação do processo do PSP, a qual aborda a definição do fluxo de materiais do empreendimento. $\mathrm{O}$ mesmo ocorre com relação à identificação visual das peças, a qual também poderia estar incluída no projeto de processos.

O planejamento do leiaute também envolve duas frentes distintas e complementares: o planejamento do macro-leiaute, envolvendo aquelas decisões que impactam todo o período da obra, realizadas durante o PSP; e o planejamento do micro-leiaute, referente a decisões que afetam somente parte do período da obra ou fase, geralmente associadas com processos específicos. Estes aspectos são objeto do planejamento de médio prazo, o qual inclui a identificação de restrições associadas com os fluxos físicos específicos decorrentes de determinados processos e serviços.

Finalmente, a confecção de peças de carga e dimensão máximas pode ser considerada como uma proteção contra incertezas resultantes tanto do extravio de peças como de eventuais mudanças na programação de montagem. Em ambos os casos, o dimensionamento de tal proteção não pode prescindir de um planejamento de médio prazo, no qual possam ser identificados os tipos mais comuns de componentes a serem empregados nas semanas seguintes. Ainda, a efetiva substituição de peças poderia ser controlada através do ciclo de planejamento de curto prazo do PCP, permitindo a identificação das causas das substituições ocorridas e a implementação de medidas visando eliminá-las.

\section{CONSIDERAÇÕES FINAIS}

Este artigo teve como objetivo principal a discussão tanto dos aspectos negativos que envolvem a coordenação entre as etapas de fabricação e montagem de estruturas préfabricadas de concreto, quanto das medidas tomadas para amenizá-los, tendo como estudo de caso a construção de um estádio de futebol padrão FIFA, na cidade de Porto Alegre-RS. Desta forma, foram apresentados os problemas correntes na coordenação do sistema produtivo em questão e os efeitos por eles gerados, seguidamente das soluções adotadas pela construtora como forma de extingui-los ou atenuá-los. 
As melhorias obtidas em termos de integração das etapas de fabricação e montagem reduziram substancialmente os estoques intermediários, possibilitando a montagem de peças vindas diretamente da fábrica. Como principais benefícios, têm-se ainda a eliminação de etapas que não agregam valor ao produto: processos de busca, localização e transporte interno - reduzindo, desta forma, o tempo de ciclo de montagem. As evidências observadas sugerem que a integração entre os processos de fabricação e montagem pode ser amplamente beneficiada pela implementação do projeto do sistema de produção (PSP) aliado a um sistema de PCP baseado no Last Planner. Evidentemente, tanto o PSP como o PCP devem incluir uma preocupação explícita com tal integração, assim como decisões quanto ao dimensionamento e composição dos estoques intermediários concebidos para lidar com a falta de integração residual. É possível observar que a ausência destas etapas pode ser uma causa relevante para os problemas de integração verificados neste estudo.

\section{REFERÊNCIAS}

EL DEBS, M. K. Concreto pré-moldado: fundamentos e aplicações. 1. ed. (2. reimpres.). São Carlos: EESC-USP, 2000.

FABRO, F. Diretrizes para implementação do Sistema Last Planner de controle da produção em empresas de estruturas metálicas. 2012. 172f. Dissertação (Mestrado em Engenharia) - Programa de Pós-Graduação em Engenharia Civil, Universidade Federal do Rio Grande do Sul, Porto Alegre, 2012.

FORMOSO, C. T.; BERNARDES, M.; ALVES, T.; OLIVEIRA, K. Planejamento e Controle da Produção em empresas de construção. Porto Alegre: NORIE/UFRGS, 2001.

OHNO, T. O Sistema Toyota de Produção: além da produção em larga escala. Porto Alegre: Bookman, 1997. 149p

OLIVEIRA, T. Plano de cargas. Revista Téchne: a revista do engenheiro civil, São Paulo, ano 15, n. 123, p. 40-43, jun. 2007.

PRIETO, C. A. Fabricación, transporte y montaje de elementos prefabricados. In: REVISTA MATERIALES, MAQUINARIA Y METODOS PARA LA CONSTRUCCIÓN (Org.). Prefabricación e industrialización en la construcción de edificios. Barcelona: Editores Técnicos Asociados, 1968. p. 61-128.

SLACK, N.; CHAMBERS, S.; HARLAND, C.; HARRISON, A.; JOHNSTON, R. Administração da produção. 1. ed. São Paulo: Atlas, 1997.

SCHRAMM, F. K. O projeto do sistema de produção na gestão de empreendimentos habitacionais de interesse social. 2004. 180f. Dissertação (Mestrado em Engenharia) Programa de Pós-Graduação em Engenharia Civil, Universidade Federal do Rio Grande do Sul, Porto Alegre, 2004.

TRIBUNAL DE CONTAS DA UNIÃO. O TCU e a Copa de 2014: relatório de situação, Brasília: TCU, ago. 2012.

TREVISO, J. P. Concreto pré-fabricado: análise do processo produtivo de estrutura de grande porte. 2012. 100f. Trabalho de Diplomação (Graduação em Engenharia Civil) - Departamento de Engenharia Civil, Universidade Federal do Rio Grande do Sul, Porto Alegre, 2013.

VENTURINI, J. Como se faz: lajes alveolares. Revista Equipe de Obra: como construir na prática, São Paulo, ano 7, n. 37, p. 28-29, jun. 2011.

VRIJHOEF, R.; KOSKELA, L. The four roles of supply chain management in construction. European Journal of Purchasing \& Supply Management, v. 6, n 3-4, p. 169-178, dez 2000 . 